\title{
NEW TECHNICAL ELECTIVE RECOGNIZING EXPERIENTIAL LEARNING IN COMPETITIVE ENGINEERING TEAMS: LESSONS FROM THE INAUGURAL TERM OF THE COURSE
}

\author{
Elizabeth Hassan \\ Engineering 1 and Department of Mechanical Engineering, McMaster University, Hamilton ON \\ hassae3@mcmaster.ca
}

\begin{abstract}
Student competitive teams provide engineering students an opportunity to develop their hands-on design, fabrication and management skills. Anecdotally, we know that many students draw on these experiences to obtain excellent post-graduation jobs; for example, automotive companies often recruit from these teams' competitions. However, in the past assigning academic credit to these activities was difficult logistically. This paper will present the methods and rationale that allowed McMaster Engineering to overcome these challenges and successfully offer a course awarding academic credit for these activities in the 2017-18 year; thought to be the first of it's kind at a Canadian engineering school.
\end{abstract}

Keywords: Experiential, Competitive Team, Extracurricular, Portfolio

\section{INTRODUCTION}

Experiential education approaches are having a resurgence of interest in higher education institutions; this year at McMaster we opened the Gerald Hatch Centre for Experiential Education and launched an internal program of seed grants to incorporate experience into all academic programs. As engineering instructors we can likely all agree that diverse technical experiences are likely to be beneficial to the professional development of our students; particularly since we practice in an academic discipline that naturally lends itself to hands-on elements, such as labs, co-op placements and capstone projects. However, the logistics of how to assign credit or grades for this kind of work is still an open question in the engineering pedagogy literature.

One activity that squarely fits most definitions of "experiential" is participation on vehicle teams in inter-university competitive vehicle teams such as Formula SAE or the World Solar Challenge. Formula SAE, which is thought to be the first collegiate competition of this type began in 1980; now there are a range of competitions around the world in which current university students compete with vehicles that they have either built or modified. These teams tend to naturally conform to the criteria laid out in Kolb and Kolb [8]; in particular, their suggestion that experiential activities draw students into a "community of practice".

Informally, the value of these student competitions is widely known, since it is common for vehicle manufacturers to recruit from these events. In recognition of this value, various attempts have been made to incorporate competitive vehicle teams into formal curricular courses $[2,4,5,6,7,9]$; many universities offer the option of using a portion of the vehicle design as a capstone project for a small group of students. In addition to the existing capstone option, in 2017-2018 McMaster Engineering introduced the option of using vehicle project work as a technical elective. This paper will outline the logistics, rationale and methods that made this possible at McMaster; ENGINEER $4 \mathrm{EX} 3$ is thought to be the first technical elective for students working on competitive vehicle teams in Canada. 
Since this is the first year of the course, this is a $n=1$ case report based on my observations as an instructor. There are many other ways that these objectives could be achieved; this paper presents the approach that was successful in our institution and that is consistent with Kolb's [8] criteria for experiential education activities, Chickering and Gamson's [3] "Seven principles" and with engineering design teaching methods in general.

\section{CURRENT COURSE}

\subsection{Motivation and Core Principles}

The intent of the course was to:

- recognize the technical learning resulting from the teams' design activities

- create ease in the students' academic schedule to support their high level of involvement

When designing the course, I drew on my experience as a former undergraduate member of a Formula SAE team and consulted with staff and faculty who frequently work with students on the teams at McMaster. I arrived at a set of principles that guided the development of the course structure. These principles were:

- It is not about tracking hours, it is about technical contribution: It is easy to spend hours polishing a part or sitting in team meetings, but these experiences are not necessarily educative.

- $\quad$ Management work is worthwhile but it is not part of the course: I recognized that development of organization and leadership skills are important outcomes for students on the team. However, since the course was a technical elective, not complimentary studies, only technical work qualified.

- Flexibility in timing and format: The students in the course were managing a wide range of competing time pressures and goals since they come from a variety of levels, projects and departments. When possible, I was flexible with deadlines and allowed them to choose their portfolio format. For example, one team asked to delay the portfolio until after a competition so they could include results.
- $\quad$ No single use deliverables: The course recognizes technical learning, the documentation of this learning was the goal of the deliverables, not to create another set of content to master.

- $\quad$ Student driven: I purposely tried to avoid interfering in how the students run the teams. Buchal [1] noted that too much faculty involvement can negatively affect team performance, and student self-determination is a core principle of experiential learning [8].

- $\quad$ Professor provides process guidance not content guidance: The range of teams involved in the course meant that no single professor could provide meaningful technical guidance to everyone. Technical advising was the responsibility of the existing faculty advisors, I provided guidance on how to prepare a portfolio aligned with the students' goals.

\subsection{Logistics}

This full-year Level 4 technical elective was open to engineering students who make significant contributions to a competitive engineering team, such as:

- Mini Baja

- Solar Car

- EcoCar3

- Formula Electric

- Concrete Toboggan

- Rocketry

It was a pass/fail course, worth 3 academic units (typical for a one term technical elective at our institution). It was open to students who were in Level III, IV or V of an engineering program with a history of work in one of the competitive engineering teams. Students in Level II were not permitted to join the course because in most cases they would not have reached the level within the team where they would be making a significant technical contribution. However, once in Level III or higher they could join the course and include their experience from past years cumulatively in the portfolio; provided it was properly documented. Many of the students in the class were in five year programs, such as 
Engineering \& Management, Engineering \& Society or Engineering \& Co-op; therefore, students in the class were not in their final year even though it was a $4^{\text {th }}$ year technical elective.

Students wishing to enter the course in the fall did so by seeking permission from their team's faculty mentor in the previous spring. Administratively, this was the same process and form for adding any other course for which permission is required, for example when waiving a prerequisite. The involvement of faculty mentors at this stage was critical to ensure only students with a high probability of success would participate. Previous involvement with the team was the criteria for admission; typical students were subsystem managers on their teams.

During the admission process the most common student question that I was asked was "How do you define significant?". I chose to answer by asking students if they planned to do one of the following:

1) Be a subsystem manager (e.g. suspension, chassis or braking)

2) Spend more than 10 hours per week on average on the team

3) Conduct at least one design-build-test cycle

These guidelines are somewhat arbitrary, particularly given that one of the core principles was "it's not about hours". However, after speaking with students this seemed to be the language that resonated most with them and how they saw their contributions. However, I was careful to emphasize that I understood that projects have their own time scales and that I had no expectation that their contributions would be linear over the year. For example, the Concrete Toboggan team's competition occurred before the reading week in winter term, so their work was heavier in fall term, lighter at the end of winter term.

\subsection{Student Interaction}

One of the challenges of a course that spans multiple departments is scheduling of instructor contact. To include as many students as possible in the course, we admitted students on co-op placement or who had a course conflict. This yielded a total of 22 students. To facilitate broad participation, we identified an additional alternate lecture slot for guest speakers, and recorded the lectures. These sessions were approximately once per month and the content was generated in response to student interests collected in September and January. The content was oriented towards career development work (e.g. reviewing job documents), supporting team activities (e.g. sponsorship guest speaker) or for giving feedback on portfolio work. One particularly useful topic was live critiques of portfolio elements gathered from publicly available online sources. This was done in fall term to help students self-assess the optimal level of technical detail in their portfolios prior to the mid-year portfolio assessment.

To ensure that students remain engaged throughout the full year course, we required weekly check ins, either digital (Slack, email or through a learning management system) or in person. This helped to ensure continual progress on their portfolios. If students missed several check ins, one of the teaching assistants followed up to check if they were having difficulties. Students frequently sent portions of their portfolio to me digitally or brought it to my office for informal feedback during the term.

Key events in each term are summarized in Table 1 on the following page. The course concluded with a digital showcase event in March. This digital event used the faculty of engineering's social media channels to share students work, for example, Instagram takeovers showing the workspaces and vehicles. Students quotes and bios were also featured on the faculty website. Participation was entirely voluntary and coordinated by faculty staff (not the instructor), and the goal of this was to increase awareness of the course and of the vehicle teams. 
Table 1: Key events in course timeline

\begin{tabular}{|l|l|}
\hline Term & Key Events \\
\hline $\begin{array}{l}\text { Spring/ } \\
\text { Summer }\end{array}$ & $\begin{array}{l}\text { Students seek permission for } \\
\text { entry from team faculty advisor }\end{array}$ \\
\hline Fall & $\begin{array}{l}\text { Lecture topics gathered } \\
\text { Lectures: Portfolio, job } \\
\text { documents, sponsorship } \\
\text { Weekly Check Ins } \\
\text { Hand in Portfolio for faculty } \\
\text { mentor and instructor feedback }\end{array}$ \\
\hline Winter & $\begin{array}{l}\text { Lectures: Portfolio, cold calling } \\
\text { Weekly Check Ins } \\
\text { Reflection assignment } \\
\text { Year end digital showcase } \\
\text { Hand in Portfolio for instructor } \\
\text { assessment }\end{array}$ \\
\hline
\end{tabular}

\subsection{Deliverables}

The students involved in this course tended to have a large number of competing time demands, therefore, the underlying philosophy of the deliverable structure was to not overburden students with single-use deliverables. Each document that was handed in served a secondary purpose for the student, most commonly as a work sample for a potential employer.

The key deliverable was the portfolio, which was assessed in December by the faculty mentors and instructor and in April by the instructor. Faculty mentor involvement allowed for verification technical experience that was outside the practice domain of the lead instructor and provided discipline specific feedback.

The portfolio had to contain at least enough documentation to satisfy the "significant contribution" criteria, but students have the option to include any projects over and above that threshold that they wished. For example, they could include projects from class, co-op or personal work, as long as their core team work was sufficient. The content of the portfolio depended on the student, their discipline and their goals; it could contain: photos, calculations, simulation results, drawings, code, block diagram and/or text. The level of documentation was set by the question "Could another engineer understand your project?". This standard at least partially dealt with rigor concerns, since peripherally involved students would have difficulty obtaining enough artifacts to complete the portfolio. The decision to pass or fail a student in the course was based on the quality of the technical content in this portfolio.

The format of this deliverable was left up to the students, this year 13/22 students made a .pdf document, 1/22 made a PowerPoint and 8/22 made a website. The choice of format was generally dictated by intellectual property concerns and their home discipline (e.g. electrical and computer engineering students tended to choose websites).

\section{OUTCOMES}

In this the first iteration of the course, every student easily surpassed the "significant technical contribution" threshold to pass the course. Anecdotally, two students moved on to jobs in the automotive industry and two moved on to graduate studies in automotive engineering. However, more detailed analysis of the impact of the course will follow in subsequent years, once we have enough students for a reasonable sample size.

\subsection{Student perspectives}

Based on informal student comments and the reflection assignment content, several general themes emerged. Students on the smaller, less hierarchical teams stated that they felt as though the course's weekly check ins kept them accountable to continuous progress on their project; with some stating that they felt more comfortable devoting more time to their team, since it was now for academic credit. Several mentioned that they were glad to be connected with support staff and services at the university through the course guest lectures and valued the feeling that there was institutional support for their activities. Many stated that the level of 
documentation of their work would have been less without the inducement of the course credit; since otherwise they would not have taken the time to do so. They saw the value in the portfolio, and that the course helped them to connect their disparate experiences into one coherent narrative.

\section{FUTURE WORK IN ENGINEER 4EX3 AND SUGGESTIONS FOR OTHER SIMILAR COURSES}

ENGINEER 4EX3 was successful this year and will be offered again in the 2018-2019 academic year; I expect a modest increase in enrollment. Next year I plan to conduct pedagogical research in the course, since we will have a larger cohort of students to study.

Next year, I plan to encourage more peer feedback on their portfolios. I expect that students will continue to have frequent schedule conflicts with the lecture time slot, so I will strive to make it easier for students to engage with lecture presentations remotely. I also plan to develop a pre-course documentation package for students not yet in the course so that they can more easily receive credit for work that they do over the summer. It is likely that in future iterations of the course the spectrum of student teams involved will be expanded beyond interuniversity vehicle competitions to other engineering student groups on campus doing sufficiently technical work.

On a philosophical level, I plan to change little about the course next year; the approach described in this paper has been met with broad student approval. The course structure has been effective, partially because of the strong existing organizational structures within the vehicle teams, excellent teaching assistant support from the faculty and small class size. If any of these factors were to change, the logistics would necessarily shift as well. For example, if class size was to dramatically increase, I would likely implement a more formal system for weekly check ins to reduce administrative load. I would advise instructors hoping to implement a similar course structure to carefully consider these types of institution-specific factors when developing their course policies.

\section{CONCLUSIONS}

The first iteration of ENGINEER 4EX3 has been effective so far, the portfolio approach has encouraged a high level of student engagement. Offering this course is one way that the faculty has signaled to students that they value the technical learning occurring in the competitive teams. The existing team structures have ensured strong technical work, and the strict admission criteria aided by the faculty mentors has reduced the risk of student failure. The flexible structure of the course has allowed it to accommodate students at a range of levels, array of projects and future career goals.

\section{Acknowledgements}

Thank you to the office of the Associate DeanUndergraduate at McMaster Engineering for their efforts in obtaining approval for the course: Dr. Ken Coley, Maria White and Dr. Joseph McDermid. Thank you to MacPherson Institute Student Partner, Irina Ghilic and teaching assistants, Marisa Kohut, Hannah McPhee and Sarah Traynor and the teams' faculty mentors.

\section{References}

[1] Buchal, R. O. The Educational Value of Student Design Competitions. Proc. Can. Eng. Educ. Assoc. (2004).

[2] Bullen, F. \& Karri, V. Design and construction of a Formula SAE racecar in a teaching and research framework. in HERDSA 74-82 (2002).

[3] Chickering, A. \& Gamson, Z. Seven principles for good practice in undergraduate education. AAHE Bull. 39, 3 7 (1987).

[4] Davies, H. C. Integrating a multi-university design competition into a mechanical engineering design curriculum using modern design pedagogy. J. Eng. Des. 24, 383-396 (2013).

[5] De-Juan, A. et al. Enhancement of Mechanical Engineering Degree through student design competition as added value. Considerations and viability. J. Eng. Des. 27, 568-589 (2016).

[6] Gadola, M. \& Chindamo, D. Experiential learning in engineering education: The role of student design 
competitions and a case study. Int. J. Mech. Eng. Educ. 0, 1-20 (2017).

[7] Hylton, P. \& Otoupal-Hylton, W. Teaching Applied Engineering Through Practicum Courses. in ASEE Annual Conference and Exposition, Conference Proceedings (2014).
[8] Kolb, A. Y. \& Kolb, D. A. Learning styles and learning spaces: Enhancing experiential learning in higher education. Acad. Manag. Learn. Educ. 4, 193-212 (2005).

[9] Verner, I. M. \& Ahlgren, D. J. Robot contest as a laboratory for experiential engineering education. $J$. Educ. Resour. Comput. 4, 2 (2004). 